\title{
O fim da Teoria da Mídia ${ }^{1}$
}

\section{Beatrice Fazi}

Doutora; University of Sussex, Inglaterra

b.fazi@sussex.ac.uk

Tradução: Luiza Carolina dos Santos

Doutoranda; Universidade Federal do Rio Grande do Sul, Porto Alegre, RS, Brasil

luizacdsantos@gmail.com

Tradução: Marcio Telles

Doutor; Universidade Federal do Espírito Santo, Vitória, ES, Brasil

tellesdasilveira@gmail.com

\section{Resumo}

Esse artigo considera o papel da teoria em geral e da teoria da mídia em específico. Ao desafiar a possibilidade de um "fim da teoria" que vem ressoando em debates sobre novas mídias, pretendo mostrar a relevância permanente da investigação teórica. Irei abordar como o ato de teorizar é frequentemente compreendido como a criação de um sistema de abstração que envolve certo grau de distanciamento da realidade que deve descrever. Irei posteriormente expor uma falsa concepção em relação a este distanciamento: por exemplo, a visão de acordo com a qual, se teorizar é abstrair a partir da observação, então abstrair é se desengajar dos fatos. Contra essa visão, irei argumentar que a abstração é intrínseca ao mundo e como o experimentamos.

\section{Palavras-chave}

Abstração. Big Data. Computação. Filosofia da Mídia. Teoria da Mídia.

\section{0 fim está próximo?}

Desde sua publicação original na revista "Wired"2 , há pouco mais de uma década atrás, muito já foi discutido a respeito de "The end of theory" ${ }^{3}$, de Chris Anderson ${ }^{4}$ (2008). Em seu texto provocativo, Anderson descreve um presente tecnológico no qual algoritmos e

\footnotetext{
1 Nota do tradutor (N. do T.): Este artigo foi originalmente publicado em inglês como "The Ends of Media Theory", na primeira edição do periódico acadêmico Media Theory, sendo traduzido para o português com autorização da autora. A versão original pode ser consultada aqui: http://journalcontent.mediatheoryjournal.org/index.php/mt/article/view/23. A palavra "ends" no título original pode ser traduzido tanto como conclusão (substantivo masculino) quanto de finalidade (locução adverbial). Tanto os termos em inglês quanto no português comportam as duas traduções. Não obstante, optamos pelo termo no singular e esta nota para reforçar o duplo sentido do texto da autora: o encerramento da teoria das mídias e qual sua finalidade.

2 A "Wired" é uma revista mensal norte-americana de tecnologia fundada em 1993 na cidade de São Francisco, Califórnia, no Vale do Silício. A revista tem como seu "santo padroeiro" o teórico das mídias Marshall McLuhan e é conhecida pela linha editorial tecno-utópica (N. do T.).

${ }^{3}$ Disponível em inglês em: https://www.wired.com/2008/06/pb-theory/ (Acesso 15 de julho de 2018) (N. do T.).
} 
softwares geram insights impossíveis para especialistas humanos. Para Anderson (2008), o regime de verdade de teorias e teóricos está "se tornando obsoleto" (sem paginação, tradução nossa) devido a alta performance e velocidade das operações computacionais que agora guiam tanto invenções quanto descobertas. São dados - na verdade, quantidades massivas deles - que ofertam a chave para descobrir os segredos do mundo. A computação possuiria uma habilidade nunca vista antes de coletar e transformar o Big Data em padrões prontos para o consumo humano, sem necessidade de experimentos, modelos e hipóteses, apenas ao permitir que "os números falem por si mesmos" (Anderson, 2008, sem paginação, tradução nossa).

A partir de diferentes perspectivas, a possibilidade do fim da teoria descrito por Anderson em 2008 tem ressoado em muitos dos discursos intelectuais sobre novas tecnologias. Aparece, por exemplo, em debates das humanidades digitais, onde o slogan "more hack, less yack" tem circulado por alguns anos. A perspectiva do fim da teoria também se reflete na preocupação popular sobre o fim do trabalho cognitivo devido à automação algorítmica e em preocupações correlatas sobre o encolhimento das faculdades intelectuais humanas em uma sociedade onde a decisão racional é cada vez mais delegada às máquinas. Além disso, a possibilidade do fim da teoria retorna na distância nunca resolvida entre o trabalho prático e o trabalho teórico, ou na perene dicotomia entre pensamento e ação. Também está presente na atual ênfase no fazer como um modo mais autêntico de engajamento público e privado com o digital.

Neste texto, gostaria de aproveitar a edição inaugural de uma nova revista acadêmica sobre teoria da mídia ${ }^{6}$ para refletir a respeito de sua condição hoje, e também para abordar o próprio conceito de teoria: um conceito celebrado por alguns, mas declarado morto por outros. Minha ambição não é oferecer um tratamento exaustivo do que poderia ser "teoria" em relação à mídia ou aos estudos de mídia. Ao invés disso, irei sinalizar algumas questões para demonstrar, do meu ponto de vista, como homenagens póstumas à teoria não são necessárias, uma vez que a paciente está viva e passa bem. Meu objetivo é oferecer algumas reflexões sobre o papel da teoria em geral e sobre o papel da teoria da mídia em particular a fim de mostrar a contínua relevância dos questionamentos e da especulação teórica.

\footnotetext{
4 Chris Anderson é um jornalista e empreendedor britânico que atuou anos na revista The Economist antes de se tornar editorchefe da Wired. Em 2006, publicou o best-seller "The Long Tail" (edição brasileira: "A Cauda Longa - A nova dinâmica de marketing e vendas: como lucrar com a fragmentação dos mercados". Rio de Janeiro: Elsevier, 2006), onde defende que, com a Internet, a receita total de diversos produtos de nicho é igual à receita total de poucos produtos com grande sucesso. Independente dos erros ou acertos de sua tese, ela substanciou muito das decisões comerciais e de curadoria das plataformas de conteúdo como Spotify, Netflix e Amazon (N. do T.)

${ }^{5}$ A expressão pode ser traduzida como "mais computação, menos blábláblá" (N. do T.).

${ }^{6}$ A revista acadêmica a que a autora se refere é Media Theory, de livre acesso e avaliação por pares, dedicada às "intervenções teóricas em todos os aspectos de mídia e comunicação", e editada por Simon Dawes, da Université de Versailles SaintQuentin-en-Yvelines (UVSQ), França. Disponível em: http://journalcontent.mediatheoryjournal.org/index.php/mt (Acesso 15 de julho de 2018).
} 


\section{Criando um Sistema Abstrato}

0 texto "The end of theory", de Anderson (2008), não foi o primeiro anúncio de uma pretensa morte da teoria e, muito provavelmente, não será o último. É possível considerar uma ambiguidade inerente ao termo "teoria" como a responsável, ao menos parcial, da má reputação que o termo com frequência possui: ainda que a origem do termo esteja clara (deriva do Grego theoria, significando contemplação e especulação) ${ }^{7 i}$, o uso do termo em geral não é tão claro assim. Na verdade, há um contraste entre o uso técnico e o coloquial do termo. Academicamente falando, uma teoria é tão potente quanto seu poder de generalização. No discurso cotidiano, entretanto, "ter uma teoria" geralmente indica pouco mais que um achismo. Em minha opinião, a discrepância é interessante por destacar como, em ambos os casos, é tanto o caráter especulativo e a tentativa de totalização do trabalho teórico que parece causar preocupação ou desagrado.

0 ato de teorizar é frequentemente compreendido como um distanciamento da realidade da qual a teoria deveria dar conta. Nesta visão caricata da atividade do teórico, se engajar na produção teórica é se recusar a participar da realidade e escolher uma vida intelectual que possui pouca semelhança com a real. Clamar pelo fim da teoria, então, ou se recusar ao engajamento teórico, é visto como uma tentativa de protestar contra este afastamento: trabalho empírico ou prático é visto como mais palpável e fazer "coisas" é considerado mais honesto do que apenas pensar sobre elas.

Para explicar e expandir este ponto, podemos considerar o modo como Fredric Jameson distingue entre teoria e filosofia. A última é "sempre assombrada pelo sonho de alguma prova infalível e autossuficiente, um sistema autônomo, um conjunto de conceitos interligados que são a sua própria causa" (JAMESON, 2009, p. 59). Teoria, ao contrário, "tem interesses estabelecidos na medida em que nunca reivindica por um sistema absoluto, uma formulação não-ideológica de si e suas 'verdades'; de fato, sempre cúmplice do ser da linguagem corrente, tem apenas a tarefa e a vocação intermináveis de minar a filosofia enquanto tal, de desvendar asserções afirmativas e proposições de todos os tipos" (JAMESON, 2009, p. 59) ${ }^{\mathrm{ii}}$. A síntese da distinção de Jameson são os esforços intelectuais do pós-estruturalismo, cujo desafio às formas institucionais e ideológicas de conhecimento foi

\footnotetext{
7 Nesse ensaio, "Ciência e Reflexão", Martin Heidegger apresenta a etimologia da noção de teoria. Ele escreve: "The word 'theory' stems from the Greek verb theōrein. The noun belonging to it is theōria. Peculiar to these words is a lofty and mysterious meaning. The verb theōrein grew out of the coalescing of two root words, thea and horaō. Thea (cf. theater) is the outward look, the aspect, in which something shows itself, the outward appearance in which it offers itself. Plato names this aspect in which what presences shows what it is, eídos. To have seen this aspect, eidenai, is to know [wissen]. The second root word in theōrein, horaō, means: to look at something attentively, to look it over, to look it closely. Thus, it follows that theōrein is thean horan, to look attentively on the outward appearance wherein what presences becomes visible and, through such sigh - seeing - to linger with it" (Heidegger, 1977: 163).
} 
acompanhado pela atenção particular aos aspectos minoritários, materiais e genealógicos do pensamento. Quando olhamos para o papel da investigação teórica na tecnocultura contemporânea, acredito ser necessário reconhecer tais debates. A perspectiva de um "fim da teoria" deveria então ser situada dentro de um contexto mais amplo de tradição de críticas ao racionalismo e ao logocentrismo. Afinal, muito antes do artigo de Anderson (e com extensão e finalidade distintas), o pós-modernismo anunciou o colapso eminente de todos os grandes discursos, narrativas e metalinguagens e criou uma nuvem de suspeita sobre modos de pensar universais e universalizantes.

Para o propósito da presente discussão, entretanto, eu não irei seguir a oposição pósmoderna entre filosofia e teoria na chave racionalista/universal ou relativista/particular. Isso se explica parcialmente pelo fato de que preciso lidar com um imenso tópico em um espaço abreviado. Mais importante, entretanto, é porque desejo ressaltar as similaridades entre filosofia e teoria, ao invés de apontar suas diferenças. Ao invés de seguir Jameson na distinção entre a transcendência da filosofia e a imanência da teoria, eu irei me focar na relação entre trabalho teórico (incluindo a filosofia), de um lado, e o conceito de atividade da abstração, de outro. É claro, teorias pós-modernas e pós-estruturalistas empregam formas de abstração bastante diferentes daquelas mobilizadas pelo iluminismo filosófico, por exemplo. Ainda assim, enquanto toda filosofia é, em algum nível, teoria, e nem toda teoria é filosofia, teorizar, do meu ponto de vista, inevitavelmente envolve abstrair. Tentativas de generalização podem ser exercidas em diferentes níveis e as denotações do conceito de uma "estrutura abstrata" podem variar imensamente. Ainda, eu diria que é a capacidade de todo trabalho teórico (filosófico ou não) abstrair para que permaneça, se não transcendente, pelo menos transcendental.

Neste sentido, proponho que para me dirigir àquilo que poderia ser a teoria no século XXI (ou àquilo a que o seu fim frequentemente anunciado poderia chegar a realizar), deveríamos abordar as formas nas quais o ato de teorizar é geralmente compreendido, tanto acadêmica quanto popularmente (e, como visto acima, pelo próprio Jameson), em termos de criar sistemas de abstração. Esses sistemas podem ser fechados e absolutos, ou abertos e relativos, ou nenhum dos dois; ainda assim, envolvem um grau de distância (teórica) da mesma realidade que este sistema pretende descrever. Esse distanciamento com frequência alienou pessoas e gerou aversão ao trabalho teórico entre estudantes e departamentos universitários. A tarefa, então, que não posso assumir completamente aqui, mas que posso ao menos apontar, é a de expor uma falsa concepção deste distanciamento; por exemplo, a visão segundo a qual, se teorizar é abstrair da observação, então abstrair ou especular seria se desengajar da realidade e dos fatos. Meu objetivo é mostrar que abstrair não é um tipo de 
afastamento contemplativo, mas que é, na verdade, intrínseco ao ato de estar no mundo e a como nós o experimentamos.

\section{Distanciamento Teórico}

O ensaio de 1937 de Horkheimer, "Teoria Tradicional e Teoria Crítica”, define teoria como "o saber acumulado de tal forma que permita ser este utilizado na caracterização dos fatos tão minuciosamente quanto possível" (1983, p. 117). 0 objetivo da teoria é explicar e interpretar sistematicamente fatos através de estruturas conceituais e sistemas de proposições dedutivas. A esse respeito, "sua validade real reside na consonância das proposições deduzidas com os fatos ocorridos. Se, ao contrário, se evidenciam contradições (Widersprueche) entre a experiência e a teoria, uma ou outra terá que ser revista" (1983, p. 117). Nesse ensaio, entretanto, Horkheimer expõe a fraqueza desta metodologia e desta definição de teoria. O que ele chama de "teoria tradicional" são na verdade formas instrumentais de conhecimento que buscam um resultado particular. Nesse sentido, a teoria tradicional não reconhece que "a relação entre hipóteses e fatos não se realiza na cabeça dos cientistas, mas na indústria" (HORKHEIMER, 1983, p. 122). Dito de outra maneira, a teoria tradicional não percebe que a ciência (e a teoria de forma geral) sempre trabalha "em conexão com os processos sociais" (HORKHEIMER, 1983, p. 121), e de acordo com suas necessidades. Ao recusar reconhecer a dimensão histórica, a teoria tradicional acaba perpetuando pressupostos ideológicos da sociedade na qual está situada. À teoria tradicional, então, Horkheimer opõe uma "teoria crítica" emancipatória da sociedade, "preocupada a todo momento com condições razoáveis de vida" (HORKHEIMER, 2002, p. $199^{8}$ ), e cujo propósito, por contraste, é acessar uma "vinculação com o todo social e a natureza" (HORKHEIMER, 1983, p. 132).

Detalhar as especificidades da teoria crítica vai além do objetivo deste ensaio. É suficiente dizer que o argumento de Horkheimer é interessante no contexto do presente artigo, pois nos auxilia a sublinhar como a teoria e o ato de teorizar não são operações que almejam deixar a realidade para trás mas, ao invés disso, estão preocupadas em como viver no mundo e como podemos evitar sermos tão absorvidos nele a ponto de perdermos uma perspectiva crítica. É, portanto relevante, em minha opinião, abordar a diferenciação entre teoria tradicional e crítica feita por Horkheimer. Isso por que, enquanto a primeira se satisfaz operando dentro de uma moldura social existente, a segunda

\footnotetext{
Na tradução brasileira, a passagem é traduzida como "teoria esta impregnada do interesse por um estado racional" (HORKEIMER, 1983, p. 124). Sugerimos a tradução acima por considerá-la mais fiel à intenção da autora, cuja citação da tradução inglesa é "dominated at every turn by concern for reasonable conditions of life" (apud HORKHEIMER, 2002b, p. 1999).
} 
está preocupada em questionar as características dessa moldura a fim de alterá-la. Neste sentido, fazer teoria (de um modo crítico), ou adotar um distanciamento teórico, envolve ir além da simples observação de um determinado dado e ir de encontro à autorreflexão. Essa autorreflexão, por sua vez, leva a reconhecer a si próprio como diferente do objeto de estudo e ainda assim parte de uma coautodeterminação.

É útil aqui situar também essas considerações no contexto da forte condenação do pensamento positivista feita pela Escola de Frankfurt. Em resumo: positivismo é uma doutrina desenvolvida na metade do século XIX pelo sociólogo e filósofo francês Augusto Comte que postulava ser o conhecimento verdadeiro, válido ou "positivo", baseado na quantificação da experiência sensorial. Para os positivistas, todas as coisas são em última instância mensuráveis e todo o conhecimento é objetivo. Reconhecidamente, a teoria crítica da Escola de Frankfurt interpretou o positivismo como uma "tendência para hipostasiar a ciência" (HORKHEIMER, 2002a, p. 63). Pensadores como Theodor Adorno e Max Horkheimer tomaram como um problema a ideia de uma teoria não-valorativa. Eles constataram a pretensão de objetividade das ciências positivistas no geral e, mais especificamente, os comprometimentos epistemológicos do "positivismo lógico" (isto é, uma versão racionalista do positivismo desenvolvida no começo do século XX que sustentava a redução de todo o conhecimento a termos lógicos). Para os teóricos críticos, o positivismo representa um modo tradicional de pensamento (e de teoria) que confronta o mundo através de categorias fixas e que possui pouca consideração pelas especificidades e contingências históricas. Além disso, e ainda mais interessante para a perspectiva do argumento que desejo desenvolver, a Escola de Frankfurt denunciou o foco do positivismo científico nos simples fatos e atacou sua falta de engajamento com as razões subjetivas (ao invés das causas objetivas) de como esses fatos existem no mundo social ou como ato da mente humana. Positivismo, em outras palavras, é visto como uma doutrina que aceita fatos empíricos de forma instrumental e sem crítica enquanto excluem a possibilidade de abordar o contexto social e humano das estruturas abstratas que dão forma a eles. 0 conformismo do positivismo com os fatos, então, é visto como uma espécie de verdade ou dogma, expressa "sob a distorção de torná-la exclusiva" (HORKHEIMER, 2002a, p. 95), e sob a expectativa de obter certos resultados para necessidades específicas.

0 trabalho teórico da Escola de Frankfurt desafiou o pressuposto de que os dados (ou números, como Anderson gostaria de colocar) podem falar por si. Ao invés disso, insistiu na distância reflexiva dos dados da experiência capaz de permitir um engajamento mais profundo e significativo com a experiência, que não mais simplesmente serviria para operar esquemas pré-determinados. Portanto, ainda que o pensamento crítico que a Escola de 
Frankfurt propôs não é praxis (e Adorno é particularmente cuidadoso ao ressaltar esse ponto; veja ADORNO, 2010), também não é mera contemplação. Ao invés disso, pensar já é um modo de agir no mundo. Abstrações, por sua vez, não devem ser descartadas, mas sim compreendidas, talvez através da produção de novas abstrações, que não são nunca idênticas aos fatos. Isso porque o pressuposto da existência de fatos puros já é, para os pensadores associados à escola de Frankfurt, uma ficção. Deste ponto de vista, portanto, distanciamento teórico é necessário para evitar que um objeto de estudo fique congelado ou fixado e para integrá-lo nas estruturas conceituais que permitam sua explicação e interpretação (mas nunca sua naturalização).

\section{Conhecimento sem Pensamento}

Em relação ao campo da teoria da mídia, é preciso focar no distanciamento teórico e o que ele pode significar no contexto desse campo. Primeiramente, deveria ser pontuado que tanto quanto não existe um conceito único de teoria, também não existe um entendimento unificado de teoria da mídia. Além disso, assim como a teoria tem, com frequência, um lugar contestado na academia, também parece que os estudos de mídia poderiam ser felizes sem seu lado teórico. Perguntar o que a teoria pretende alcançar nos estudos de mídia supõe considerar sua especificidade teórica em relação às outras investigações intelectuais (como aquelas dos estudos culturais, da sociologia e dos estudos da ciência e da tecnologia, por exemplo) que também informam grande parte de nosso entendimento atual sobre as mediações tecnológicas.

Proponho exatamente isto ao retornar, mais uma vez, ao artigo de Anderson na Wired (2008). 0 artigo não foi direcionado aos teóricos da mídia, mas a forma como poderiam respondê-lo é capaz de clarear o escopo e as implicações dos debates teóricos no campo. A esse respeito, devemos começar observando que o argumento de Anderson para o fim da teoria refere-se à obsolescência do método científico. Anderson está preocupado não com o papel da especulação nas humanidades, mas sim com a função de hipóteses, experimentação e, acima de tudo, modelos nas ciências. Isso não é negar que sua colocação pertença também ao trabalho das ciências humanas. Na verdade, ela carrega implicações distintas em cada caso. Entretanto, é interessante notar que o alvo explícito de Anderson é a metodologia da ciência teórica, antagonizada por aquela das tecnologias aplicadas.

Anderson observa que estamos vivendo "na idade mais mensurável da história" (2008, sem paginação, tradução nossa). Essa condição, ele argumenta, pede por "uma abordagem completamente diferente" (2008, sem paginação, tradução nossa) do 
conhecimento. 0 modus operandi do Google exemplifica, na visão de Anderson, a virada epistemológica da computação. 0 Google não esperava, ou sequer sabia, qualquer coisa de sua publicidade antes de se tornar o maior peão no tabuleiro. Antes, ele conquista esta posição por usar "dados melhores" e "ferramentas analíticas melhores" (ANDERSON, 2008, sem paginação, tradução nossa). Hipóteses testáveis são coisas do passado, uma vez que o Big Data nos permite o luxo de não nos importarmos com causas objetivas ou razões subjetivas e nos focarmos apenas em correlações. 0 exemplo principal de Anderson é o trabalho de sequenciamento genético do biotecnólogo e geneticista americano J. Craig Venter. "Capacitado por sequenciadores e supercomputadores de alta velocidade que analisam estatisticamente os dados que eles produzem", Anderson explica, "Venter passou do sequenciamento individual de organismos para o sequenciamento de um ecossistema completo", descobrindo, no processo, "centenas de espécies de bactérias e outras formas de vida anteriormente desconhecidas" (ANDERSON, 2008, sem paginação, tradução nossa). Venter, entretanto, não é um Darwin moderno, uma vez que ele não está preso "no jeito antigo de fazer ciência". Diferente de Darwin, diz Anderson, Venter não sabe como as novas espécies se parecem, como sem comportam ou qual sua morfologia. Na verdade, Venter "não pode dizer quase nada sobre as espécies que descobriu" (ANDERSON, 2008, sem paginação, tradução nossa). Tudo o que possui é "um pontinho estatístico" que, ainda assim, o permitiu avançar "mais do qualquer outro de sua geração" (ANDERSON, 2008, sem paginação, tradução nossa) na biologia.

Para Anderson, esse exemplo ilustra seu argumento de que "podemos parar nossa busca por modelos", uma vez que podemos "jogar números nos maiores clusters de computadores que o mundo já viu e deixar os algoritmos estatísticos encontrarem padrões onde a ciência não consegue" (ANDERSON, 2008, sem paginação, tradução nossa). Por esses comentários, dá para perceber a maneira na qual o artigo de Anderson recebe de bom grado a perspectiva de nosso mundo contemporâneo estar se tornando uma espécie de "quarto chinês". No famoso experimento mental de John Searle, um falante monolinguístico de inglês é trancado em um quarto e recebe um conjunto de escritas chinesas, assim como regras para estabelecer correlação entre seus elementos. 0 ponto de Searle é que o falante de inglês poderia se tornar "tão b[o]m ao seguir as instruções" (1997, p.63), que "-do ponto de vista de alguém que esteja do lado de fora do quarto" as respostas dele ou dela seriam "indistinguíveis de falantes nativos de chinês". Mesmo assim, essa pessoa não falaria realmente a língua e não a compreenderia; ele ou ela apenas correlacionaria símbolos, sem se importar com seus significados. 
Searle utiliza esse exercício de pensamento para pontuar que os programas de inteligência artificial podem ter sintaxe, mas não semântica e, portanto, são capazes de apresentar respostas corretas e ainda assim incapazes em entender seu significado. Entretanto, em relação à expectativa epistêmica de um fim da teoria a partir da automação computacional, essa preocupação não parece importante, e com certeza não importa para Anderson, que está atacando o papel dos modelos na ciência teórica por eles constituírem uma abstração do imediatismo da correlação. De fato, como argumentam Morrison e Morgan (1999, p.11), modelos na ciência são mediadores investigativos que representam "alguma faceta do mundo, ou alguma faceta de nossas teorias sobre o mundo, ou ambos ao mesmo tempo" (tradução nossa), e, assim, um resíduo humanista na atividade de pensar que, segundo Anderson, deve ser descartada.

Acertadamente, o filósofo Bernard Stiegler (2016) descreveu essa visão epistêmica como uma forma de conhecimento sem pensamento ${ }^{9}$. A observação de Stiegler é tão conceitualmente aguda quanto alarmante, pois supõe que o fim da teoria, conforme anunciada por Anderson, poderia significar o fim do entendimento e, consequentemente, de faculdades cognitivas como a alfabetização e o discernimento. Adicionaria que a interpretação de Anderson das práticas tecnocientíficas atuais pode ser compreendida como uma forma de hiperpositivismo, uma vez que deposita confiança absoluta nos dados. Entretanto, sua visão também desafia o projeto positivista do século $\mathrm{XX}$, uma vez que descarta os marcos de verificabilidade (ou falibilidade) da ciência que são considerados chave para o "conhecimento positivo". Igualmente, a ideia de Anderson sobre o fim da teoria carrega um caráter empirista explícito que, ao mesmo tempo em que celebra a instrumentalização da observação tecnocientífica (e o computador como o instrumento de todos os instrumentos, neste caso), também rejeita, em certo sentido, o empirismo ao negar a utilidade de qualquer observador, levando ao esvaziamento da própria pesquisa empírica da fonte de seu poder inferencial.

\section{Teoria da Mídia depois da Virada Computacional}

O que, então, poderiam os teóricos da mídia fazer quando confrontados com a possibilidade de conhecimento sem pensamento? Do meu ponto de vista, eles deveriam defender a possibilidade de pensamento no conhecimento, mesmo após a virada

\footnotetext{
9 “O conhecimento automatizado celebrado por Anderson não precisa mais ser pensado. Na era da implementação algorítmica da matemática aplicada em máquinas computadorizadas, não há mais nenhuma necessidade para o pensamento: ele é concretizado na forma de automações algorítmicas que controlam sistemas de captura de dados e que, portanto, tornam-no obsoleto" (Stiegler, 2016, p. 49, tradução nossa).
} 
computacional na cultura e na sociedade. Se trabalhar teoricamente é trabalhar tendo como objetivo a compreensão, então, tomando emprestadas as palavras de Adorno, "deve-se manter a teoria, precisamente sob a coerção geral em direção à práxis em um mundo funcional e pragmático" (2010, p. 273, tradução nossa). Ainda incluiria que deveríamos nos apegar particularmente à teoria da mídia, cuja necessidade é exacerbada pela presente compulsão para que os dados (ou pelo menos o Big Data) substituam a hermenêutica, tanto funcional quanto pragmaticamente. Minha reivindicação aqui é: ainda que se possa reconhecer que nem toda a teoria da mídia é "teoria das novas mídias" e que nem todo o campo é estritamente preocupado com o digital, os estudos de mídia, em suas dimensões teóricas, estão em posição privilegiada para entender as implicações epistemológicas das tecnologias computacionais.

Nesse sentido, a teoria da mídia se abre, e pode se sobrepor, ao que atualmente é chamado de filosofia da mídia. Dentro da academia, a expressão "filosofia da mídia" pode denotar o contexto germânico específico no qual esta vertente emergiu, e pode, portanto, se referir aos esforços acadêmicos no sentido de tentar criar uma disciplina capaz de repensar o 'medium' em relação às subjetividades humanas e não-humanas. Entretanto, o termo "filosofia da mídia" também pode ser apropriado e utilizado de forma mais ampla, para indicar uma investigação teórica multifacetada dos modos de ser e experimentar que são engendrados por, ou que existem em relação a, sistemas de mídia em geral. É neste sentido que eu adoto o termo aqui, reconhecendo a ruptura que este pode sinalizar em relação à agenda dos estudos de comunicação, que os estudos de mídia adotaram, em parte, por questões históricas e genealógicas.

Filosofia da Mídia, entendida no sentido aqui proposto, não se opõe à teoria da mídia, mas ao invés disso é sua aliada na busca pela criação de conceitos adequados para abordar as formas como agimos, percebemos e pensamos em um mundo altamente mediado tecnicamente. Retornando à minha colocação anterior que o ato de teorizar pode ser entendido em termos de abstração, gostaria de acrescentar que a relação entre o trabalho teórico em mídia e a abstração é o de criar conceitos. Em outras palavras, uma das principais finalidades da teoria da mídia é a conceitualização: é criar estruturas conceituais através de meios abstratos e explicar e interpretar fatos através e em relação a tais estruturas. Um distanciamento teórico e reflexivo é importante para permitir que a conceitualização seja feita a partir de problematizações. Entendo a diferença entre conceito e problema da mesma forma que Gilles Deleuze. Para ele, "não se cria conceitos, a não ser em função dos problemas", no sentido de que "[t]odo conceito remete a um problema, a problema sem os quais não teria sentido, e que só podem ser isolados ou compreendidos na medida de sua 
solução" (Deleuze e Guattari, 2010, p. 24). Problematização, então, vem antes da conceitualização, já que os conceitos da filosofia (e da teoria também) são criados para fazer algo: eles devem abordar um problema com o qual nós (como cultura e sociedade, ou simplesmente como sujeitos pensantes) somos confrontados.

Para Deleuze, a liberdade de identificar e construir um problema é a liberdade que caracteriza tanto a natureza quanto o destino da filosofia (e da teoria). Este argumento deleuziano, que deriva de Bergson, é de certa forma uma instância pouco usual na história do pensamento, que, discutivelmente, preferiria fazer da filosofia (e da teoria) o espaço intelectual onde as soluções (e não os problemas) são encontrados. Entretanto, para Deleuze, as questões que o pensamento intelectual pode colocar são mais importantes do que suas respostas. Para ele, "é o problema que orienta, condiciona, engendra as soluções", ainda que "estas não se assemelham às condições do problema" (DELEUZE, 2006, p. 299).

Em relação à posição deleuziana, pode-se argumentar que a teoria da mídia (e também a filosofia da mídia) oferece o espaço intelectual para pensar a computação como problema; como um problema que precisa de conceitos relevantes. A teoria da mídia é capaz de pensar o computacional e suas implicações epistemológicas, pois não toma as tecnologias digitais como instrumentos ou ferramentas para saber mais, mas como objetos de estudo sobre os quais devemos saber mais. A partir dessa visão, o que a mídia computacional pode explicar não é importante; ao invés disso, é a própria mídia computacional que deve ser explicada. Além disso, o argumento deleuziano sobre a problematização fornece mais evidências de que adotar uma instância teórica não é se afastar do mundo, mas, ao contrário, uma forma de comprometer-se com ele. É possível expandir o posicionamento deleuziano de forma que esteja de acordo com outra tradição bastante distinta do pensamento, aquela da Escola de Frankfurt discutida anteriormente. Desta forma, pode-se afirmar que a teoria da mídia é capaz de produzir pensamento a partir do processo de geração de conhecimento (refiro-me aqui ao argumento de Stiegler) após a virada computacional, precisamente porque pode pensar as transformações do pensamento pelas "tecnologias pensantes".

No pouco espaço que me resta eu gostaria de trazer outra voz que pode nos auxiliar nesta afirmação, mostrando mais uma vez a relação entre teoria e abstração como um dos pontos determinantes da finalidade (e não do fim) dos projetos teóricos. Essa é a voz do matemático e filósofo Alfred North Whitehead, que publicou sua principal obra, "Processo e Realidade”, em 1929 (2010), menos de duas décadas antes de Adorno e Horkheimer escreverem a sua ("Dialética do Esclarecimento", 1944/1985) e que possuía motivos distintos, mas igualmente fortes, para endossar a recusa da tendência positivista de seu tempo. 
O trabalho de Whitehead não é uma teoria crítica da sociedade, mas um esforço cosmológico de construir uma ontologia que poderia funcionar vis-a-vis a matemática e a ciência do século XX. Ainda, como os escritores da Escola de Frankfurt, Whitehead também discordava profundamente da premissa de que algo como um "fato bruto" (Whitehead, 2006) pudesse existir. Existem muitos elementos técnicos e obscuros na filosofia de Whitehead, cuja introdução e explicação excedem o escopo e foco deste ensaio. 0 que eu gostaria de chamar atenção é para a maneira como Whitehead ressalta, veementemente, que dados não são realidade, mas registros quantificáveis dela. 0 que o "materialismo científico" (ou seja, o positivismo) do seu tempo celebrava como 'matéria', então, era uma abstração do imediatismo da experiência. A última é vista pelos positivistas como um conjunto de fatos neutros e vazios, que precisam de interpretação. Para Whitehead, entretanto, o pensamento (qualquer consideração mental ou "polo", no vocabulário de Whitehead) não é externo aos fatos, mas interno a estes e à constituição do mundo.

Como essas considerações se relacionam com nossas preocupações? Primeiro, Whitehead permite que possamos compreender o papel central de processos de abstração em todo o ato experimentado. Ainda mais interessante, o argumento de Whitehead é tanto epistemológico quanto ontológico: existir é abstrair. Toda vez que teóricos são acusados de serem muito abstratos, podemos nos referir a Whitehead e considerar sua visão que não existe um acesso não-abstrato aos fatos. É a abstração que nos permite 'preender' (um verbo bem whitehediano) a realidade. Portanto, abstrair não é se distanciar do real, mas ao contrário, é um acesso a ele e uma forma de produzi-lo em realidade.

Segundo, introduzir a posição de Whitehead nos permite um distanciamento da crítica à especulação, isto é, ressaltar o lado especulativo de que a teoria é capaz. A esse respeito, eu diria que a observação Whiteheadiana que a abstração é um modo fundamental da experiência pode ser conectado à teoria da mídia. Podemos ressaltar que a abstração que a teoria da mídia aborda é, em última instância, outra abstração: a tecnologia. Isso é, por outro lado, uma abstração que deveria ser situada entre muitas outras abstrações, como a linguagem, por exemplo. Nesse sentido, abstração se torna não apenas um modo de investigação mas um objeto (ou parte do objeto) de investigação. Nos movemos então de uma epistemologia para uma ontologia ao destacar que a abstração é constitutiva não apenas de como alguém pode conhecer o mundo, mas também de como alguém pode estar no mundo. Abstração não é exterior e separada do objeto, mas pode ser localizada dentro dele. Com Whitehead, o distanciamento teórico que esse ensaio explorou se torna o espaço necessário para a realidade (da tecnologia, como uma abstração entre outras) emergir e se desenvolver. 


\section{Referências}

ADORNO, T. W. 'Who's Afraid of the Ivory Tower? A Conversation with Theodor W. Adorno', in: G. Richter (ed.) Language Without Soil: Adorno and Late Philosophical Modernity. Translated by G. Richter. New York: Fordham University Press, 2010, pp. 227-238.

ANDERSON, C. 'The End of Theory: The Data Deluge Makes the Scientific Method Obsolete', Wired. June 23, 2008 [Online]. Available at: https://www.wired.com/2008/06/pb-theory/ (Accessed: 1 July 2017) .

DELEUZE, G. Diferença e repetição. Trad. Luiz Orlandi e Roberto Machado. 2ª Ed. Rio de Janeiro: Graal, 2006.

DELEUZE, G.; GUATTARI, F. 0 que é a filosofia? 3a Ed. Trad. Bento Prado Jr. e Alberto Alonso Muñoz. São Paulo: Ed.34, 2010.

HEIDEGGER, M. 'Science and Reflection', in: The Question Concerning Technology and Other Essays. Translated by W. Lovitt. New York: Garland Publishing, 1977, pp. 155-182.

ADORNO, T. W.; HORKHEIMER, M. Dialética do Esclarecimento: fragmentos filosóficos. Trad. Guido Antonio de Almeida. Rio de Janeiro: Zahar, 1985.

HORKHEIMER, Max. Teoria tradicional e teoria crítica. In: Textos escolhidos / Walter Benjamin, Max Horkheimer, Theodor W. Adorno, Jürgen Habermas. Coleção Os Pensadores. Trad.: José Lino Grunnewald et al. 2.ed. São Paulo: Abril Cultural, 1983, p. 117-154.

HORKHEIMER, Max. Eclipse da Razão. Trad.: Sebastião Uchoa Leita. São Paulo: Centauro, 2002a.

HORKHEIMER. "Traditional and Critical Theory". In: HORKHEIMER, Max. Critical Theory: selected essays. Trad. M.J. O'Connell. Londres: Continuum, 2002b, p. 188-243.

JAMESON, F. Valences of the Dialectic. London: Verso, 2009.

MORRISON, M.; MORGAN, M. S. 'Model as Mediating Instruments', in: MORGAN, M. S. and MORISSON, M. (eds) Models as Mediations. Perspectives on Natural and Social Science. Cambridge: Cambridge University Press, 1999, pp. 10-37.

SEARLE, J. R. Mentes, cérebros e programas. In: TEIXEIRA, J. F. (Org.). Mentes, Máquinas e Consciência: uma introdução à filosofia da menta. Trad. Cléa Regina de Oliveira Ribeiro. São Carlos, SP: Editora UFSCar, 1997, p. 61-94.

STIEGLER, B. The Automatic Society. Volume 1: The Future of Work. Translated by D. Ross. Cambridge: Polity, 2016.

WHITEHEAD, A. N. A Ciência e o Mundo Moderno. São Paulo: Paulus, 2006.

WHITEHEAD, A. N. Processo e realidade: ensaio de cosmologia. Trad. Maria Teresa Teixeira. Lisboa: Centro De Filosofia Universidade Lisboa, 2010. 


\title{
The ends of Media Theory
}

\begin{abstract}
This article considers the role of theory in general, and of media theory specifically. By challenging the prospect of the 'end of theory' that has been resonating in debates about new media, I aim to show the continued relevance of theoretical enquiry. I will address how the act of theorising is often understood in terms of creating an abstract system-a system that involves a degree of distance from the reality that it is meant to describe. I will then expose a false conception pertaining to this distance; i.e. the view according to which, if to theorise is to abstract from observation, then to abstract is to disengage from facts. Contra this view, I will argue that abstraction is intrinsic to the world and to how we experience it.
\end{abstract}

\section{Keywords}

Abstraction. Big Data. Computation. Media Philosophy. Media Theory.

Recebido em 10/07/2019

Aceito em 16/10/2019 
HEIDEGGER, 1977:63 (na nota de rodapé). 'Science and Reflection', in The Question Concerning Technology and Other Essays. ii JAMESON, 2009, p. 59. Valences of the Dialectic. 